\title{
The Stable Repression of Mesenchymal Program Is Required for Hepatocyte Identity: A Novel Role for Hepatocyte Nuclear Factor $4 \alpha$
}

\author{
Laura Santangelo, ${ }^{1}$ Alessandra Marchetti, ${ }^{1}$ Carla Cicchini, ${ }^{1}$ Alice Conigliaro, ${ }^{1}$ Beatrice Conti, ${ }^{2}$ \\ Carmine Mancone, ${ }^{2}$ Jessica A. Bonzo, ${ }^{3}$ Frank J. Gonzalez, ${ }^{3}$ Tonino Alonzi, ${ }^{2}$ \\ Laura Amicone, ${ }^{1}$ and Marco Tripodi ${ }^{1,2}$
}

\begin{abstract}
The concept that cellular terminal differentiation is stably maintained once development is complete has been questioned by numerous observations showing that differentiated epithelium may undergo an epithelial-to-mesenchymal transition (EMT) program. EMT and the reverse process, mesenchymal-to-epithelial transition (MET), are typical events of development, tissue repair, and tumor progression. In this study, we aimed to clarify the molecular mechanisms underlying these phenotypic conversions in hepatocytes. Hepatocyte nuclear factor $4 \alpha$ (HNF4 $\alpha)$ was overexpressed in different hepatocyte cell lines and the resulting gene expression profile was determined by real-time quantitative polymerase chain reaction. HNF $4 \alpha$ recruitment on promoters of both mesenchymal and EMT regulator genes was determined by way of electrophoretic mobility shift assay and chromatin immunoprecipitation. The effect of HNF $4 \alpha$ depletion was assessed in silenced cells and in the context of the whole liver of HNF4 knockout animals. Our results identified key EMT regulators and mesenchymal genes as new targets of HNF $4 \alpha$. HNF $4 \alpha$, in cooperation with its target HNF1 $\alpha$, directly inhibits transcription of the EMT master regulatory genes Snail, Slug, and HMGA2 and of several mesenchymal markers. HNF $4 \alpha$-mediated repression of EMT genes induces MET in hepatomas, and its silencing triggers the mesenchymal program in differentiated hepatocytes both in cell culture and in the whole liver. Conclusion: The pivotal role of HNF $4 \alpha$ in the induction and maintenance of hepatocyte differentiation should also be ascribed to its capacity to continuously repress the mesenchymal program; thus, both HNF $4 \alpha$ activator and repressor functions are necessary for the identity of hepatocytes. (HePATOLOGY 201 1;53:2063-2074)
\end{abstract}

$\mathrm{E}$ pithelial-to-mesenchymal transition (EMT) is the process by which polarized cells of the epithelium lose cell-cell connections and acquire the mesenchymal characteristics of motility and invasiveness. The reverse process, mesenchymal-to-epi- thelial transition (MET), often occurs at a site secondary to the original EMT population. The dynamic EMT/MET processes are essential for embryonic development and wound repair and initiate the pathological states of fibrosis and metastatic cancer. ${ }^{1}$

\footnotetext{
Abbreviations: ChIP, chromatin immunoprecipitation; EMSA, electrophoretic mobility shift assay; EMT, epithelial-to-mesenchymal transition; HNFo, hepatocyte nuclear factor $4 \alpha ; M E T$, mesenchymal-to-epithelial transition; $m R N A$, messenger $R N A ; q P C R$, quantitative polymerase chain reaction; RT-qPCR, reverse transcription-quantitative polymerase chain reaction; siRNA, small interfering RNA; TGFß, transforming growth factor $\beta$.

From the ${ }^{1}$ Department of Cellular Biotechnologies and Hematology, Pasteur Institute - Cenci Bolognetti Foundation, Sapienza University of Rome, Rome, Italy; ${ }^{2}$ National Institute for Infectious Diseases L. Spallanzani, Institute of Research and Cure of Scientific Character, Rome, Italy; and the ${ }^{3}$ Laboratory of Metabolism, Center for Cancer Research, National Cancer Institute, National Institutes of Health, Bethesda, MD.

Received July 14, 2010; accepted February 19, 2011.

Supported by Cancer Research Italian Foundation (FIRC), Ministry of Health, MIUR Ministry of University and Scientific Research, and Waldensian Church.

L. S. is recipient of a "Giorgio Ferraresi" FIRC 2010-2012 Fellowship for Cancer Research.

Address reprint requests to: Marco Tripodi, Dipartimento di Biotecnologie Cellulari ed Ematologia, Sezione di Genetica, Molecolare, Sapienza University of Rome, Viale Regina Elena 324, 00161 Rome, Italy. E-mail: tripodi@bce.uniroma1.it; fax: (39)-06-4462891.

Copyright $@ 2011$ by the American Association for the Study of Liver Diseases.

View this article online at wileyonlinelibrary.com.

DOI 10.1002/hep.24280

Potential conflict of interest: Nothing to report.

Additional Supporting Information may be found in the online version of this article.
} 
Several master regulators of EMT have been identified. The transcriptional repressors of the Snail family, Snail (Snai1) and Slug (Snai2), induce EMT partly through direct inhibition of E-cadherin gene transcription. $^{2,3}$ Snail also acts as a point of signal integration for many other inducers of EMT, including Wnt, transforming growth factor $\beta$ (TGF $\beta)$, Notch, and estrogens. ${ }^{4}$ It is generally assumed that completion of MET involves reverse sequential modulation of the mechanisms that led to EMT, thereby permitting reacquisition of the epithelial phenotype; however, the molecular mechanisms driving MET are largely unknown.

In the liver, EMT/METs have been postulated for several terminally differentiated cell types including parenchymal cells. ${ }^{5}$ Concerning hepatocytes, whereas there are solid experimental data supporting EMT occurrence in culture ${ }^{6-8}$ and in vivo, ${ }^{9}$ evidence of MET remains elusive.

It has been shown that the orphan nuclear receptor hepatocyte nuclear factor $4 \alpha$ (HNF $4 \alpha)$ orchestrates the expression of several epithelial markers in hepatocytes. ${ }^{10}$ HNF $4 \alpha$ confers to fibroblasts an epithelial-like morphology ${ }^{11}$ and re-establishes a differentiated phenotype to invasive hepatocellular carcinoma. ${ }^{12}$ These findings, together with our previous observations showing that HNF4 $\alpha$ counteracts Snail-dependent down-regulation of epithelial markers, ${ }^{6}$ suggest that $\mathrm{HNF} 4 \alpha$ may act as an MET-inducing factor in hepatocytes. Recently, an HNF $4 \alpha$-mediated EMT suppression was observed in an in vivo model of hepatic fibrosis. ${ }^{13}$ However, the molecular mechanisms allowing HNF $4 \alpha$ to induce MET and to maintain the differentiated liver epithelium have not been fully explored.

In this study, we provide evidence on the molecular mechanisms by which HNF $4 \alpha$, inducing MET, maintains the hepatocyte-differentiated phenotype. Our data revealed that this role of $\mathrm{HNF} 4 \alpha$ is intrinsically linked to active repression of the mesenchymal program expression. In undifferentiated human and murine hepatoma cells, HNF $4 \alpha$ overexpression correlated with down-regulation of mesenchymal markers. Transcriptional analysis and chromatin immunoprecipitation (ChIP) assays lead us to identify as direct targets of $H N F 4 \alpha$ repression the master regulators of the EMT program Snail, Slug, and HMGA2. A stable binding of HNF $4 \alpha$ on regulatory sequences of mesenchymal genes was found in differentiated hepatocytes while experimentally induced EMT/MET oscillations correlate with its dynamic recruitment. Notably, the relevance of HNF $4 \alpha$ in the active repression of mesenchymal genes was confirmed in vivo. The mesenchymal markers vimentin, desmin, and $\alpha$-smooth muscle actin were identified in histological samples from mice with hepatocyte-specific deletion of $H n f 4 \alpha .^{14}$ Our data highlight the role of HNF $4 \alpha$ in controlling the hepatic epithelial phenotype by repression of master EMT regulators and mesenchymal genes.

\section{Materials and Methods}

Cell Culture Conditions. BW1J and Hep3B cells were grown as reported in the Supporting Methods.

RNA Extraction, Reverse-Transcription, and $R T-q P C R$. Total RNA extraction and real-time quantitative polymerase chain reaction (qPCR) were performed as reported in the Supporting Methods. RTqPCR primer sequences are listed in Supporting Tables 2 and 3.

Immunofluorescence and Immunohistochemistry. For immunofluorescence/immunohistochemistry analysis, cells and liver slices were treated as reported in the Supporting Methods.

Bioinformatic Analysis of Promoters. Regulatory sequences (up to $2 \mathrm{~kb}$ upstream of transcription start site) were obtained from ENSEMBL (http://www.ensembl.org) and submitted to MatInspector Professional (release 8.0, Genomatix, Munchen, Germany) and cREMaG (http:www.cremag.org) to identify putative HNFs consensus sites. A transcription factor matrix symmetry score value $>0.84$ was accepted as the cutoff for further analysis by way of electrophoretic mobility shift assay (EMSA) and ChIP assays.

Statistical Analysis. Statistical analysis was conducted using the Student $t$ test. All the tests were two-sided, and $P$ $<0.05$ was considered statistically significant.

$\boldsymbol{E M S A}$. Nuclear protein extraction and EMSA were performed as reported ${ }^{6}$ and as described in the Supporting Methods. Probe sequences are reported in Supporting Table 1.

ChIP Assay. ChIP assays in cultured cells and in liver samples were performed as reported ${ }^{15}$ and described in the Supporting Methods.

RNA Interference. MMH D3 cells were transfected with small interfering RNA (siRNA) oligonucleotides against HNF $4 \alpha$, or LaminA/C (5'-GGUGGUGACGAUCUGGGCUUUTT-3') using ON-TARGET plus SMARTpool siRNA (J-065463-05/06/07/08; Dharmacon, Lafayette, CO) by Lipofectamine 2000 (Invitrogen, San Diego, CA). RNA and protein were harvested after 48 hours.

\section{Results}

Ectopic HNF4a Induces MET in Hepatoma Cells. It has been reported that HNF $4 \alpha$ promotes the 
expression of epithelial markers and liver products in dedifferentiated hepatoma cells. ${ }^{16}$ Considering the dual role of this factor as both a transcriptional activator and repressor, we aimed to assess whether the molecular mechanisms by which HNF $4 \alpha$ drives the epithelial differentiation include the down-regulation of mesenchymal genes. To address this question, we used the murine hepatoma cell line BW1J that lacks endogenous expression of HNF $4 \alpha$ and displays mesenchymallike morphology and invasive behavior. ${ }^{17}$ Retrovirusmediated overexpression of HNF $4 \alpha$ induced BW1J cells (BW-H4) to acquire a cuboidal, tightly packed hepatocyte-like morphology and to reduce motility and invasivity (Supporting Fig. 1).

As expected, ectopic HNF $4 \alpha$ up-regulated the expression of the liver-specific genes transthyretin $(T T R)$, albu$\min (A l b)$, and hepatocyte nuclear factor $1 \alpha(H n f l \alpha)$ and the epithelial markers E-cadherin ( $C d h 1)$ and cytokeratin 18 (Krt18). Notably, BW-H4 cells also showed the down-regulation of the dedifferentiation marker $\alpha$ fetoprotein $(\alpha F P)$; the mesenchymal genes $\mathrm{N}$-cadherin (Cdh2), $\alpha$-smooth muscle actin (Acta2), vimentin (Vim), and fibronectin $(F n 1)$; and the invasivity marker metalloproteinase $9(\mathrm{Mmp} 9)$ (Fig. 1A). Similar results were obtained in human hepatoma Hep3B cells overexpressing HNF $4 \alpha$ (3B-H4) (Supporting Fig. 1). Overall, these data indicate that $\mathrm{HNF} 4 \alpha$ plays a role in MET regulation by modulating epithelial differentiation and mesenchymal gene expression.

HNF4a Directly Inbibits the EMT Master Gene Snail. Because of the complexity in morphological changes observed in HNF $4 \alpha$-overexpressing hepatoma, we hypothesized a general EMT repressor role for HNF $4 \alpha$. Therefore, our analysis focused on known EMT master regulators. First, we considered the transcriptional repressor Snail, a key EMT inducer in several epithelial cell types, ${ }^{18,19}$ including hepatocytes. ${ }^{6}$ In BW-H4 cells, HNF $4 \alpha$ ectopic expression caused a significant down-regulation of endogenous Snail mRNA and protein levels (Fig. 1B). Similar data were obtained in 3B-H4 cells (Supporting Fig. 2).

Bioinformatics analysis of both mouse and human Snail promoters revealed the presence of two putative HNF $4 \alpha$ binding sites (depicted in Fig. $1 \mathrm{E}$ and Supporting Fig. 2). To test the hypothesis of a direct transcriptional repression, we first analyzed in BW1J cells whether HNF $4 \alpha$ modulated the activity of a mouse Snail promoter fused to a luciferase reporter. This assay showed that Snail promoter activity was repressed by HNF $4 \alpha$ in a dose-dependent manner (Fig. 1C). A Snail promoter mutated in both HNF $4 \alpha$ consensus sites was used as control.
Next, we tested the ability of HNF $4 \alpha$ in vitro to bind the identified consensus sequences by means of EMSA. As shown in Fig. 1D, indicated mouse Snail probes were shifted by nuclear extracts from BW-H4 cells (lane 2 in both panels) and supershifted by antiHNF $4 \alpha$ antibody (lane 3) but not by control antitubulin antibody (lane 4), thus demonstrating the presence of a specific binding site for HNF $4 \alpha$ on the mouse Snail promoter. An excess of wild-type, but not of the mutated cold probe, faded the shift (lanes 5, 6), whereas the same nuclear extracts failed to shift the labeled mutated probes (lanes 8-10). Similar results were obtained on the human Snail promoter in 3B-H4 cells (Supporting Fig. 2).

Finally, in order to verify the HNF $4 \alpha$ recruitment to the Snail promoter in vivo, we performed ChIP experiments with nuclear extracts from differentiated hepatocytes (MMH-D3), which express HNF $4 \alpha$ at a level comparable with those found in adult liver. ${ }^{20}$ HNF $4 \alpha$ was recruited to both consensus sites on the Snail promoter together with the nuclear receptor corepressor NCoR (Fig.1E). This result correlates HNF $4 \alpha$ binding on the Snail promoter to the transcriptional inactivation of the Snail gene. Similar results were obtained by analyzing the human Snail promoter in 3B-H4 cells (Supporting Fig. 2). These data demonstrate that Snail is a direct target of HNF $4 \alpha$ transcriptional repression activity.

HNF1 $\alpha$ Cooperates with HNF4a to Suppress Snail Expression. We next investigated the potential involvement of HNF $1 \alpha$, another transcription factor pivotal in hepatocyte differentiation, in the induction of MET. The rationale for our investigation was based on the following considerations: (1) HNF1 $\alpha$ is an HNF $4 \alpha$ target gene ${ }^{21}$; (2) the comparative bioinformatic analysis of murine and human Snail promoters revealed HNF $1 \alpha$ consensus sequences in the proximity of HNF $4 \alpha$ binding sites; and (3) HNF $1 \alpha$ and HNF $4 \alpha$ physically $^{22}$ and functionally ${ }^{23}$ interact to cooperatively regulate a large fraction of liver transcriptome. ${ }^{24}$

Notably, ectopic HNF1 $\alpha$ caused a significant decrease in Snail mRNA levels in both murine and human hepatoma (Fig. 2A). Moreover, HNF1 $\alpha$ cooperates with $\mathrm{HNF} 4 \alpha$ in repressing Snail promoter activity, as measured by luciferase assay (Fig. 2B), and binds to its identified consensus on human Snail promoter in EMSA (Supporting Fig. 2). Mutation of the HNF $1 \alpha$ binding site abolishes both binding (Supporting Fig. 2) and Snail repression without influencing HNF $4 \alpha$-mediated repression (Fig. 2B). Furthermore, ChIP experiments revealed that $\mathrm{HNF} 1 \alpha$ binds in vivo to both murine and human Snail promoters (Fig. 2C). 

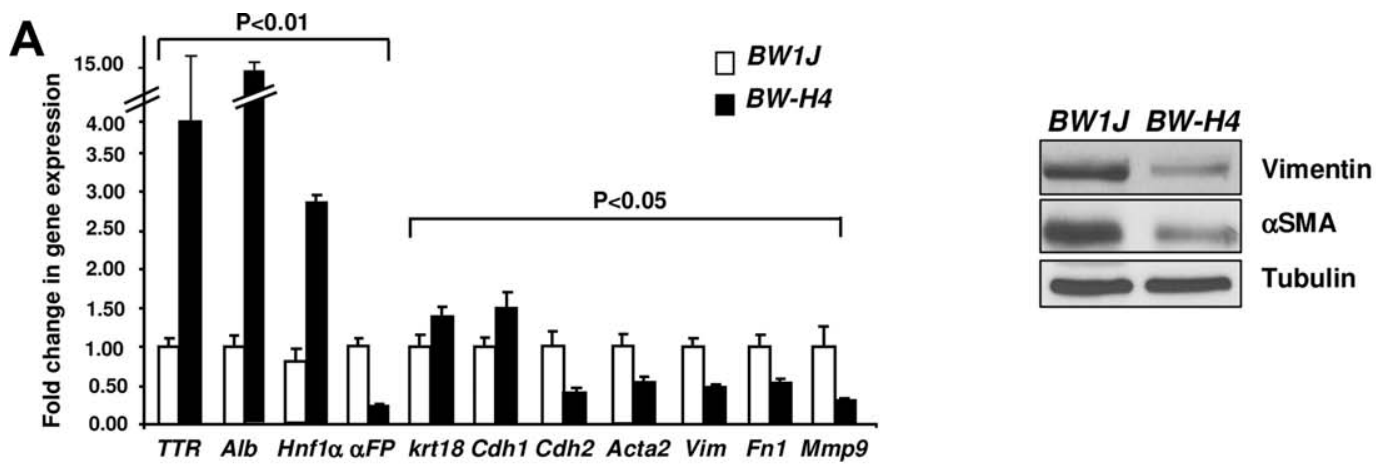

B
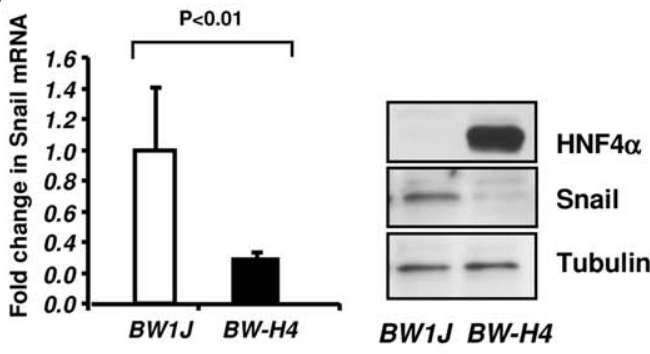

D

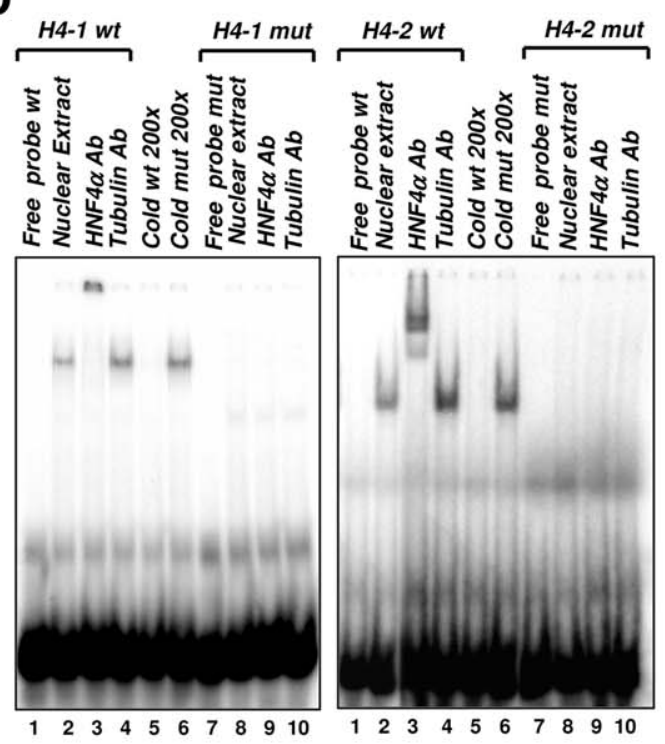

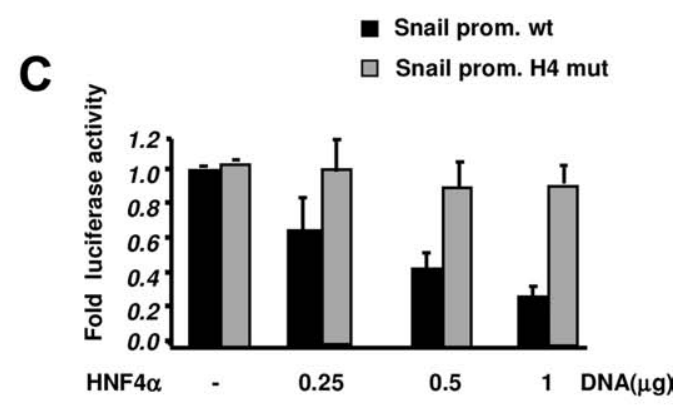

E SNAIL Mus musculus
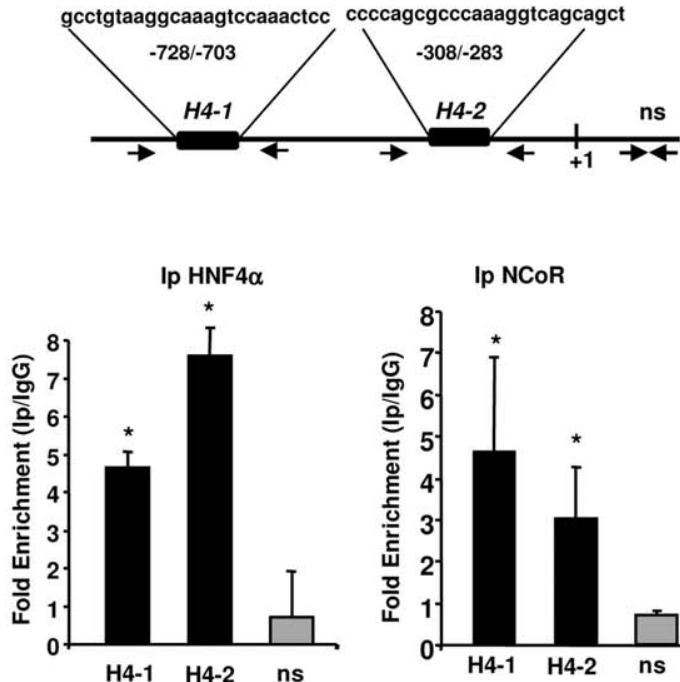

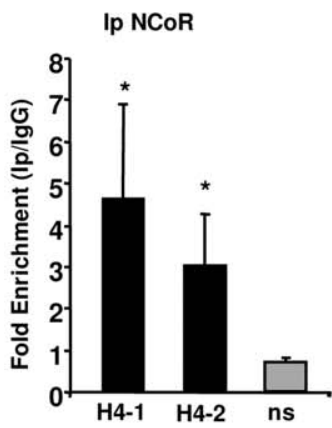

Fig. 1. Ectopic HNF4 $\alpha$ expression in BW1J cells down-regulates mesenchymal markers and induces transcriptional repression of Snail. (A) Left: qPCR analysis on BW-H4 cells. Values are expressed as gene expression fold of change versus mock-infected BW1J cells with means \pm SD for triplicate samples ( $\Delta \Delta \mathrm{Ct}$ method; $P<0.05, P<0.01$; Student $t$ test). Right: Western blot analysis of mesenchymal markers vimentin and $\alpha$-smooth muscle actin ( $\alpha$ SMA) and, as control, tubulin in BW-H4 and BW1J cells. (B) Left: qPCR analysis of endogenous Snail mRNA level in BW-H4 versus parental BW1J cells. The values are calculated as in (A). $P<0.01$. Right: Western blot analysis of Snail, HNF4 $\alpha$, and, as control, tubulin as in (A). (C) Luciferase assay. Murine wild-type (wt) or mutant (mut) Snail promoter activity measured in BW1J cells transfected with the indicated amount of the expression vector for HNF4 $\alpha$. Luciferase activity was normalized for cotransfected $\beta$-galactosidase activity and expressed as fold change relative to basal Snail promoter activity (mean \pm SD of three independent experiments performed in triplicate). (D) EMSA assays with probes designed on the indicated HNF4 $\alpha$ consensus binding sites on murine Snail promoter (from -728 to -703 and from -308 to -283 with respect to the transcriptional start +1 ). Nuclear extracts from BW-H4 cells were analyzed for the binding to wild-type (lanes 1-6 in both panels) or mutated (lanes 7-10 in both panels) HNF4 $\alpha$ consensus. The specificity of binding was tested by means of anti-HNF4 $\alpha$ (lane 3 of both panels) or unrelated anti-tubulin (lane 4 in both panels) antibodies. Wild-type (wt) and mutant (mut) cold competitor probes were added in a 200 -fold excess (lanes 5, 6 of both panels). (E) qPCR analysis of ChIP assays with anti-HNF4 $\alpha$ and anti-NCoR antibodies on chromatin from MMH-D3 hepatocytes. ChIP on specific HNF4 $\alpha$ consensus compared with nonspecific genomic regions (ns) are both normalized to total chromatin input and expressed as fold enrichment above background (control immunoprecipitation with immunoglobulin G [Ip/lgG]). The murine Snail promoter consensus sites for HNF4 $\alpha$ (H4-1 from -728 to -703 and H4-2 from -308 to -283 with respect to the transcriptional start +1 ) are schematically depicted as black boxes; the regions amplified and the unrelated sequences used as negative control (ns) are depicted as arrows. Mean \pm SD values from three independent experiments are reported with statistical significance. ${ }^{*} P<0.05$. 

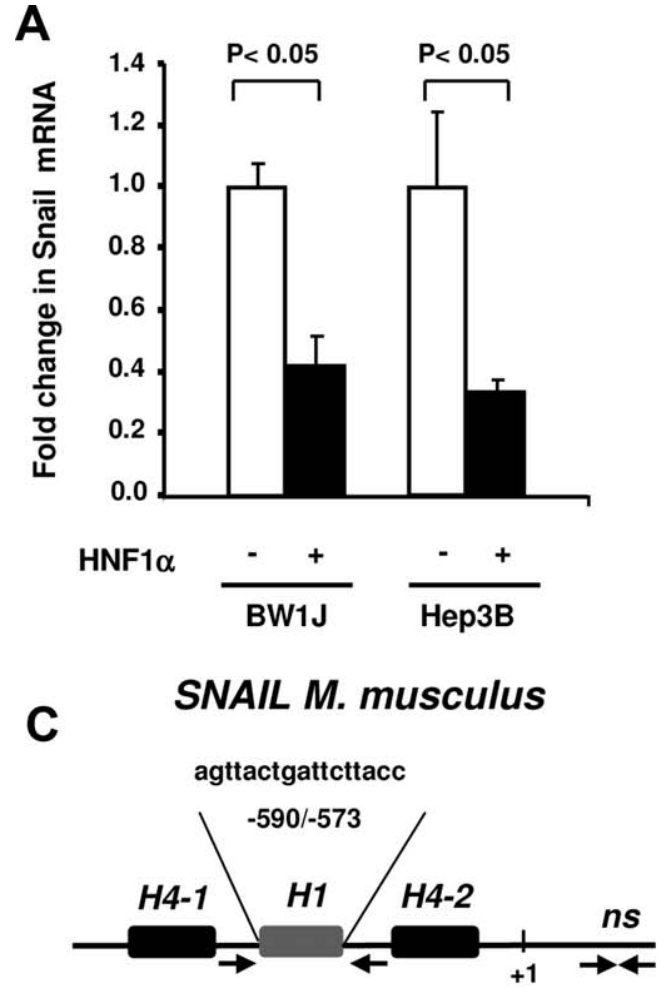

Ip HNF1 $\alpha$

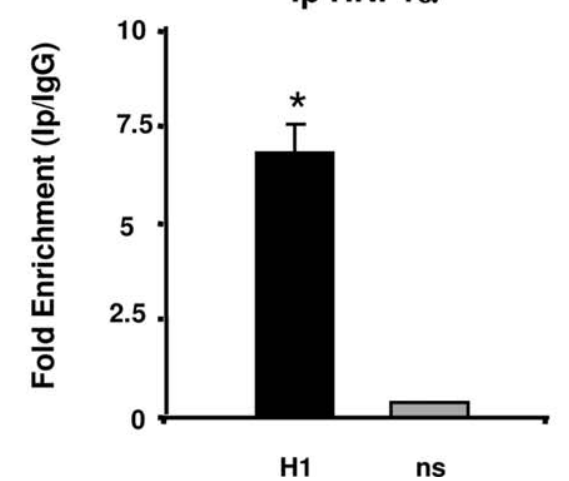

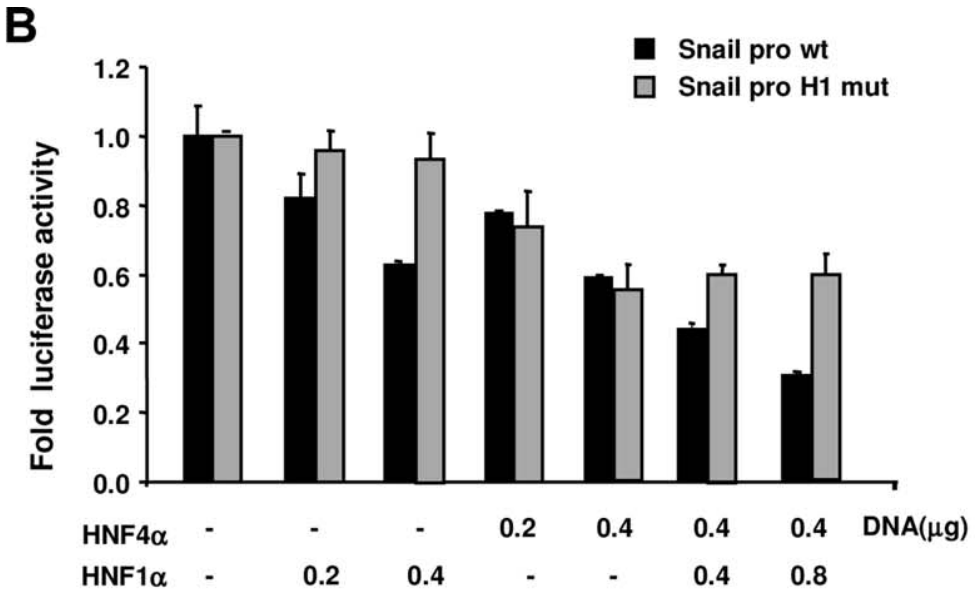

SNAIL H. sapiens

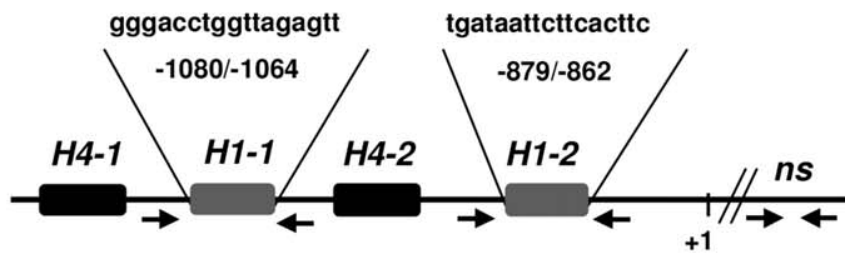

Ip HNF1 $\alpha$

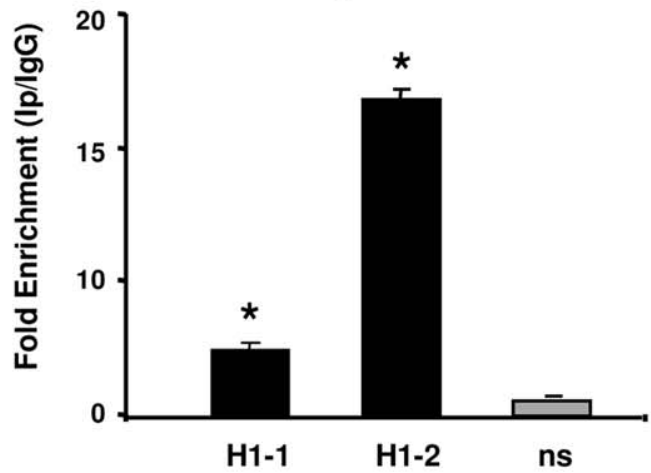

Fig. 2. HNF1 $\alpha$ cooperates with HNF4 $\alpha$ in direct transcriptional repression of Snail gene. (A) qPCR analysis of Snail in parental and HNF1 $\alpha$ transfected BW1J and Hep3B cells calculated using the $\Delta \Delta$ Ct method $(P<0.05)$. (B) Luciferase assay of Snail promoter activity performed in BW1J cells transfected with either or both HNF1 $\alpha$ and HNF4 $\alpha$ expressing constructs. Mutation of the HNF1 consensus was also tested. Luciferase activities were normalized for $\beta$-galactosidase activity and expressed as fold of change (mean $\pm \mathrm{SD}$ of three independent experiments). (C) qPCR analysis of ChIP assay with anti-HNF1 $\alpha$ antibody on chromatin derived from parental murine MMH-D3 hepatocytes (left) and human HNF4 $\alpha$-transfected Hep3B hepatomas (3B-H4) (right). Controls are as described in Fig. 1E. HNF1 $\alpha$ consensus sites are depicted as gray boxes and the amplified region is depicted with black arrows. ${ }^{*} P<0.05$.

Overall, these results demonstrate that direct HNF $4 \alpha$ repression of Snail gene transcription is reinforced by its target gene HNF1 $\alpha$.

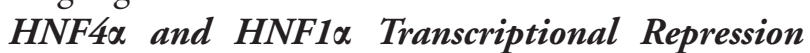
Includes Other EMT Master Genes and Mesenchymal Markers. We extended our analysis to the other member of the vertebrate Snail family, Slug (Snai2), ${ }^{3}$ and to HMGA2, a high-mobility group protein recently proposed to be an inducer of Snail and Slug gene expression. ${ }^{25}$ The promoters of these genes have putative binding sites for both HNF $4 \alpha$ and HNF $1 \alpha$. Ectopic expression of HNF $4 \alpha$ and HNF $1 \alpha$ in Hep3B caused a significant decrease of Slug and HMGA2 mRNA levels (Fig. 3A,C). Similar to what was observed for the Snail gene, this repression activity is exerted through a direct recruitment of HNFs on both promoters, as demonstrated by ChIP experiments (Fig. 3B,D). 

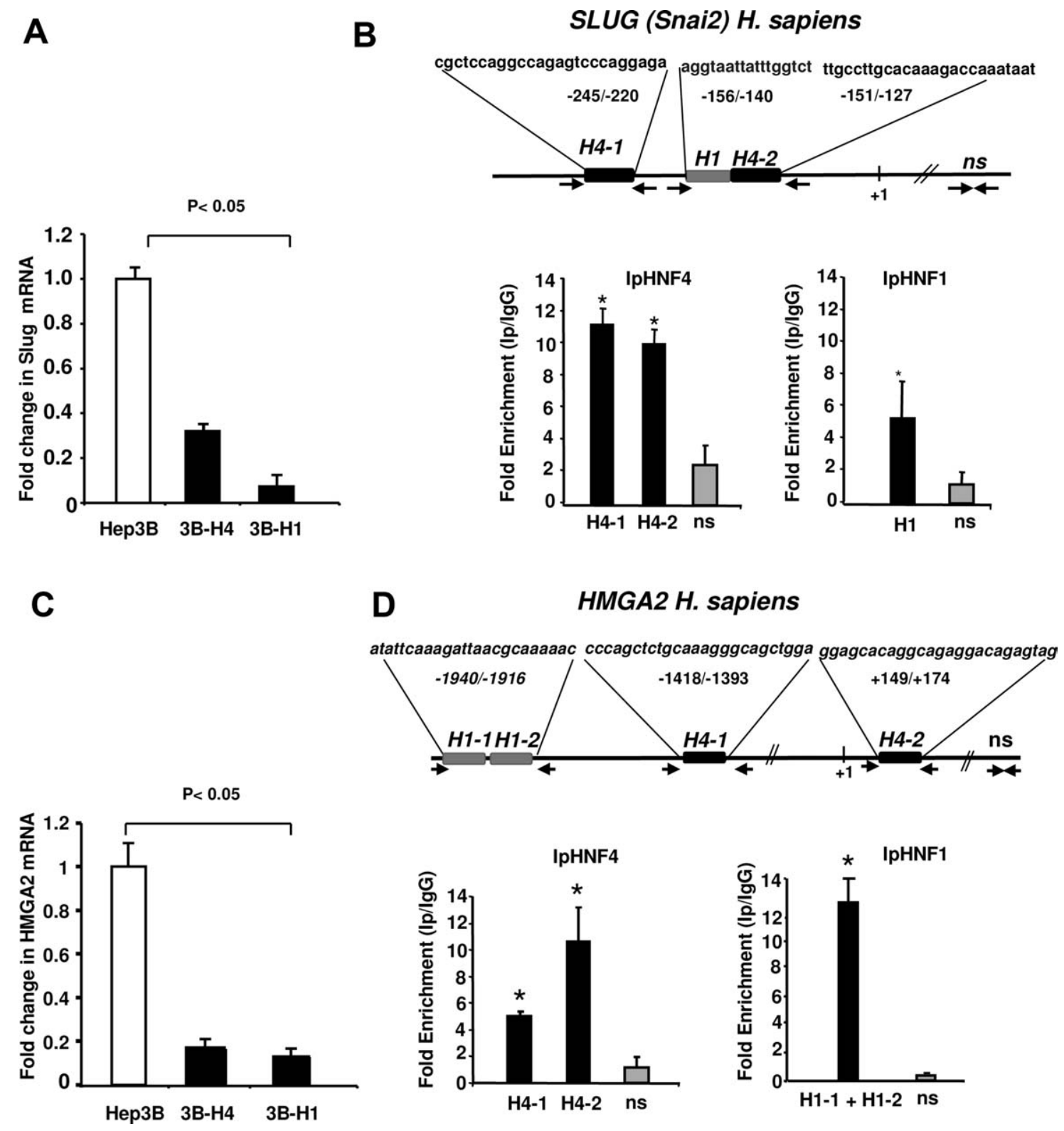

Fig. 3. HNF4 $\alpha$ and HNF1 $\alpha$ transcriptional repression target other EMT regulators. (A) qPCR analysis of Slug expression in Hep3B cells transfected with the expression vectors for HNF4 $\alpha(3 \mathrm{~B}-\mathrm{H} 4)$ or HNF1(3B-H1) or empty vector as control calculated using the $\Delta \Delta \mathrm{Ct}$ method $(P<$ 0.05). (B) qPCR analysis of ChIP assays with anti-HNF4 $\alpha$ and HNF1 $\alpha$ antibodies on chromatin derived from Hep3B cells cotransfected with both HNF4 $\alpha$ and HNF1 $\alpha$ constructs. Controls are as described in Fig. 1E. Black and gray boxes indicate the consensus sites for HNF4 $\alpha$ (H4-1 and H4-2) and HNF1 $\alpha(\mathrm{H} 1)$, respectively. Black arrows indicate the region amplified. (C) qPCR analysis of HMGA2 expression in Hep3B cells transfected with the expression vectors for HNF4 $\alpha$ (3B-H4) or HNF1 $\alpha 1$ (3B-H1) or empty vectors as control calculated using the $\Delta \Delta C$ Ct method $(P<$ 0.05). (D) qPCR analysis of ChIP assays with anti-HNF4 $\alpha$ (left panel) and HNF1 $\alpha$ (right panel) antibodies on chromatin derived from Hep3B cells cotransfected with both HNF4 $\alpha$ and HNF1 $\alpha$ constructs. Controls are as described in Fig. 1E. Consensus sites for HNF4 $\alpha$ (H4-1 and H4-2) and HNF1 $\alpha$ (H1-1 and H1-2) are depicted by black and gray boxes, respectively. PCR-amplified regions are depicted as in B.

Because the promoter analysis of some mesenchymal genes up-regulated in EMT identified putative HNF $4 \alpha$ and HNF $1 \alpha$ binding sites, we extended our ChIP analysis to fibronectin, vimentin, and desmin. Interestingly, we found that in MMH-D3 hepatocytes, endogenous HNFs are recruited to these promoters together with N-CoR (Fig. 4A). Overall, these results suggest a more general role for HNFs as direct repressors of the mes- enchymal differentiation program, through targeting both EMT master and mesenchymal genes.

Epithelial-Mesenchymal-Epithelial Transitions Correlate with Dynamic HNF4a Recruitment to Target Genes. We have demonstrated that TGF $\beta 1$ induces EMT in MMH hepatocytes. ${ }^{7} \mathrm{MMH}$ cells provided a reliable model to study the reverse process, MET. In fact, as shown in Fig. $4 \mathrm{~B}-\mathrm{C}$, TGF $\beta 1$ withdrawal is 
A

ChIP Fn1 promoter
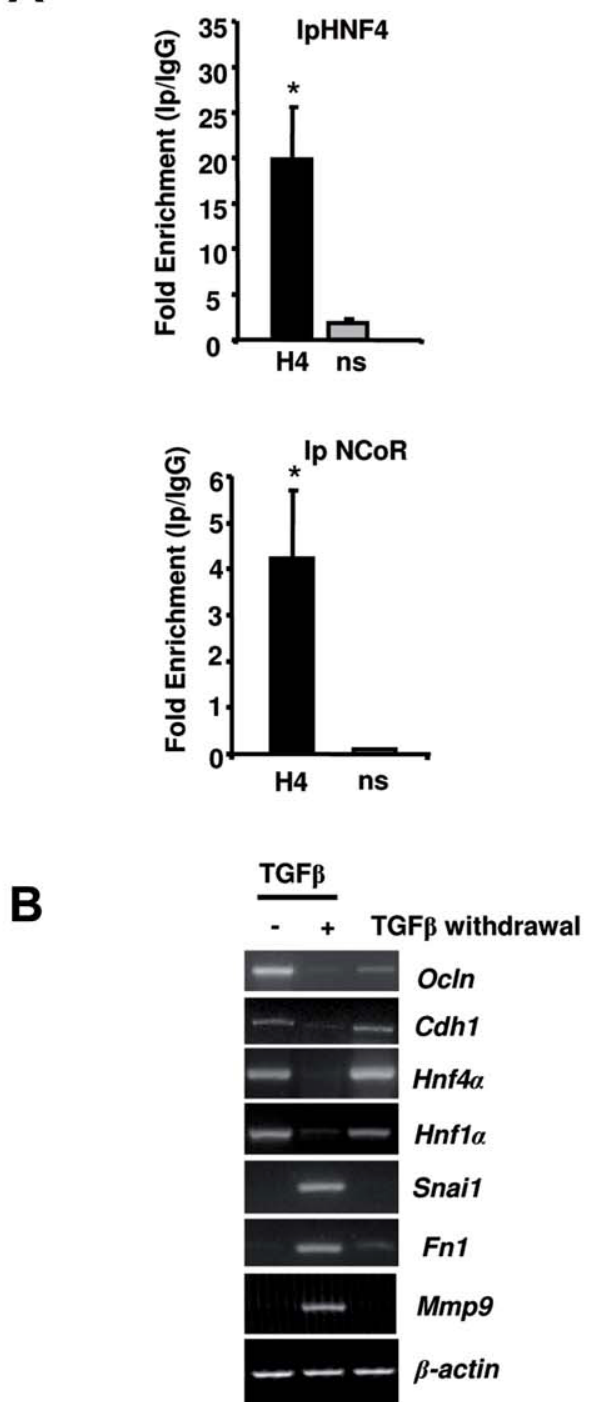

ChIP Vim promoter
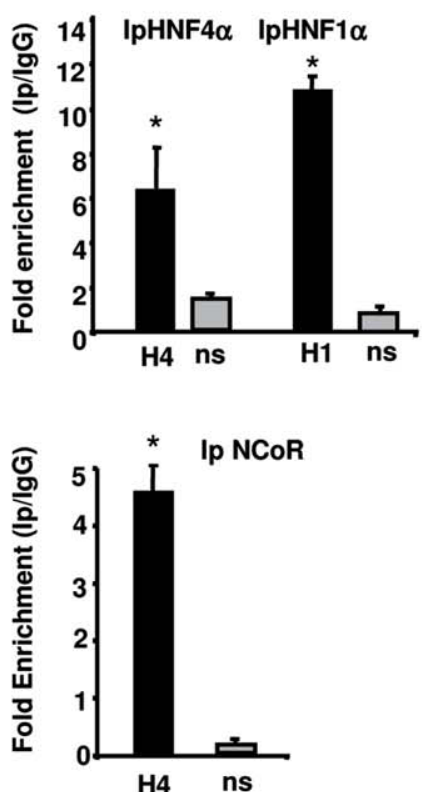

ChIP Des promoter
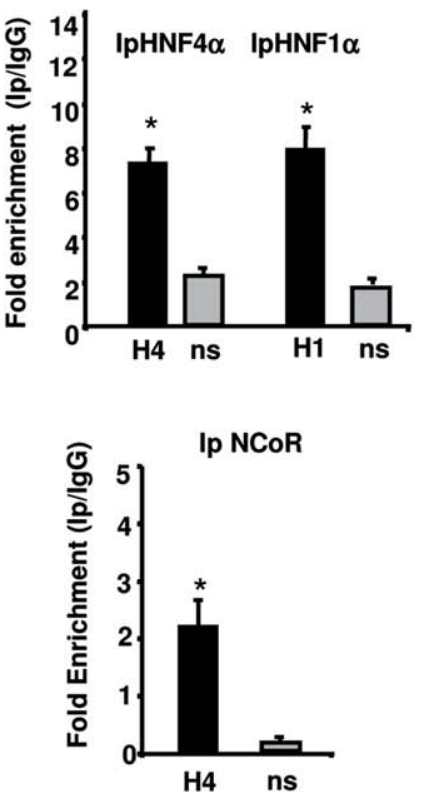
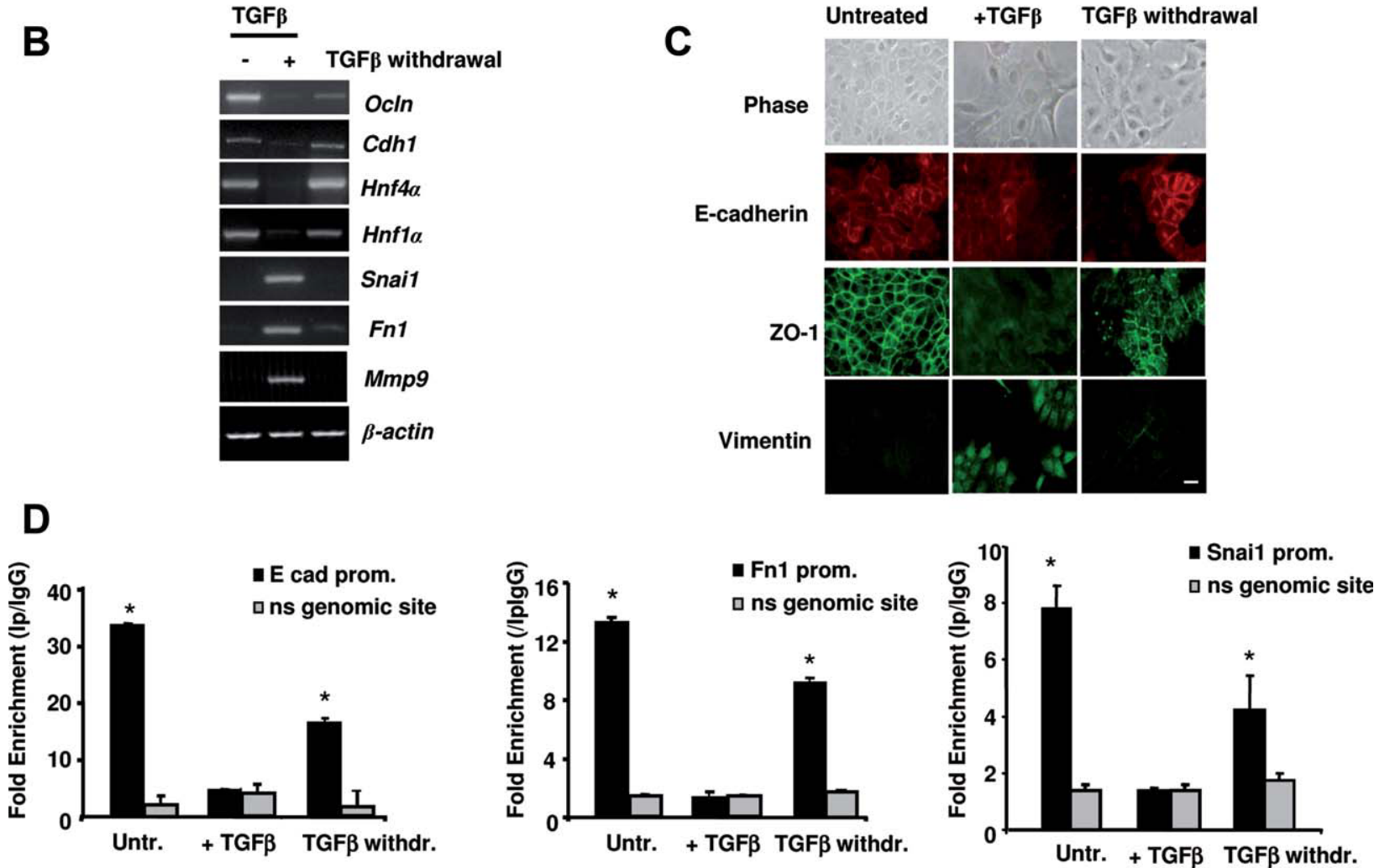

Fig. 4. The epithelial-mesenchymal-epithelial transitions in hepatocytes correlate with dynamic HNF4 $\alpha$ binding to target genes. (A) ChIP assay in $\mathrm{MMH}$ hepatocytes showing the endogenous HNF4 $\alpha$ and NCoR binding to mouse fibronectin, vimentin, and desmin promoters compared with unrelated sequences used as negative control (ns). HNFs consensuses are shown in Supporting Fig. 3. $* P<0.05$. (B) Evidence of the mutually exclusive expression of epithelial (occludin [Ocln], E-cadherin [Cdh1]), Snail [Snai1]) and mesenchymal (fibronectin [fn1], metalloproteinase 9 [Mmp9]) markers in MMH-D3 cells treated with TGF $\beta 1$ as shown by way of semiquantitative reverse-transcription PCR analysis. (C) Phase-contrast micrographs and immunofluorescence staining for E-cadherin, ZO-1, and vimentin in MMH-D3 cells treated with TGF $\beta 1$ for 48 hours $(+\operatorname{TGF} \beta)$ and 72 hours after cytokine withdrawal (TGF $\beta$ withdrawal). Scale bar, $40 \mu \mathrm{m}$. (D) qPCR analysis of ChIP assay with anti-HNF4 $\alpha$ antibody on chromatin derived from MMH-D3 hepatocytes treated with TGF $\beta 1$ for 48 hours ( + TGF $\beta$ ) and 72 hours after cytokine withdrawal (TGF $\beta$ withdrawal). Controls are as described in Fig. 1E. The HNF4 $\alpha$ consensus sites amplified are: $-308 /-283$ for Snai1, $-245 /-220$ for Fibronectin (Fn1), and $-226 /-201$ for E-cadherin. ${ }^{*} P<0.05$. 
sufficient to restore the epithelial morphology and polarity and to revert EMT-regulated gene expression. We made use of differentiated MMH-D3 hepatocytes to analyze the endogenous $\mathrm{HNF} 4 \alpha$ recruitment on chromatin during both EMT and MET. As shown in Fig. 4D, ChIP experiments highlighted a dynamic HNF $4 \alpha$ binding to the promoters of Snail, fibronectin, and E-cadherin genes during EMT/METs. These data demonstrate the presence of endogenous HNF $4 \alpha$ on EMT genes during spontaneous MET, thus implying its requirement for their negative regulation.

HNF4a Impairment Is Sufficient to Induce Mesenchymal Gene Expression in Hepatocytes. As shown above, overexpression of $\mathrm{HNF} 4 \alpha$ is sufficient to repress both EMT inducers and mesenchymal markers in dedifferentiated hepatoma cells, whereas in differentiated hepatocytes the endogenous factor is recruited, together with corepressors, on promoter regions of the same genes. These results suggest that the HNF $4 \alpha$-mediated repression of EMT program could actively contribute to the maintenance of the hepatocyte phenotype. To test this hypothesis, we knocked down endogenous HNF $4 \alpha$ expression in MMH cells. When HNF $4 \alpha$ was efficiently silenced at the mRNA and protein levels (Fig. 5A) and expression of its positively regulated target gene apoC3 (APOC3) (Fig. 5C) decreased, we observed up-regulation of EMT master Snail (Snai1) and Slug (Snai2); mesenchymal genes vimentin (Vim), desmin (Des), and $\mathrm{N}$-cadherin (Cdh2); and metalloproteinases $M m p 2$ and $M M p 9$ (Fig. 5C). As expected, in depleted cells no occupancy of HNF $4 \alpha$ site on Snail promoter was observed (Fig. 5B). Furthermore, Hnf $4 \alpha$ knockdown cells displayed, when compared with control cells, down-regulation of the cell polarity marker ZO-1, delocalization of E-cadherin, increased staining for the mesenchymal marker desmin (Fig. 5D), and increase in motility as assessed by migration assays (Fig. 5E).

These results suggest a novel conceptual vision of the determination of the epithelial identity where repression of the mesenchymal program is a further and perhaps equally important function of $\operatorname{HNF} 4 \alpha$. Furthermore, the expression of the mesenchymal program was investigated in hepatocyte-specific Alb$H n f 4 \alpha^{-l-}$ knockout mice. ${ }^{14}$ Figure 6A shows that, beyond the described hypertrophic phenotype, ${ }^{14}$ Alb$H n f 4 \alpha^{-1-}$ hepatocytes exhibit a marked histological staining to the mesenchymal cytoskeletal proteins desmin, vimentin, and $\alpha$-smooth muscle actin. The hepatocyte identity of these cells was also highlighted by confocal microscopy costaining of albumin and $\alpha$ smooth muscle actin. As shown in Supporting Fig. 4, qPCR analysis of total mRNA preparations from Alb-
$H n f 4 \alpha^{-1-}$ liver assessed an up-regulation of mesenchymal markers as well as Snail (Snai1). Moreover, $\mathrm{HNF} 4 \alpha$ in vivo recruitment on mesenchymal gene promoters was analyzed via ChIP assay. The enrichment for the promoter amplicons was approximately seven- to eight-fold for fibronectin and nearly two-fold for snail (Fig. 6B). Overall, these data demonstrate that $\mathrm{HNF} 4 \alpha$ is required for both the maintenance of hepatic epithelial differentiation and induction of MET, through the up-regulation of epithelial gene expression and direct down-regulation of EMT genes.

\section{Discussion}

The orphan nuclear receptor HNF $4 \alpha$ has long been considered a key factor in hepatocyte differentiation. $^{26,27}$ Evidence for its pivotal role in controlling the hepatic phenotype arises from a number of observations: (1) it controls the development of the hepatic epithelium and liver morphogenesis, ${ }^{11}$ (2) it triggers epithelial polarization of embryonic cells, ${ }^{28}$ and (3) it re-establishes the epitheliality in dedifferentiated hepatomas. ${ }^{16}$ Recent integrated approaches have extended its putative biological function to a broad repertoire of target genes that participate in other cellular functional categories (cell cycle, apoptosis, stress response, and cancer). ${ }^{29}$ The majority, if not all, of these observations assigns to $\mathrm{HNF} 4 \alpha$ a positive role in the regulation of gene expression.

The main finding of our work is to ascribe to HNF $4 \alpha$ a novel general "anti-mesenchymal" role through the orchestrated repression of both master EMT regulators and mesenchymal genes. We provided evidence for the repression of the mesenchymal gene program executed not only during an HNF $4 \alpha$-mediated MET process induced in undifferentiated hepatocarcinoma cells but also in the normal fully differentiated hepatocytes that stably retain the epithelial phenotype. In dedifferentiated hepatomas, ectopic HNF $4 \alpha$ was sufficient to down-regulate Snail, Slug, HMGA2, vimentin, and fibronectin expression. In differentiated hepatocytes, endogenous HNF $4 \alpha$ was found stably recruited to the promoters of EMT inducers and mesenchymal genes. Interestingly, Snail, HMGA2, and vimentin were classified as putative HNF $4 \alpha$ targets by way of an in silico search. ${ }^{29}$ Our ChIP data provide functional evidence for this prediction, thus indicating that HNF $4 \alpha$-mediated induction of the epithelial phenotype is linked to its repression of EMT genes. The interpretation of an HNF $4 \alpha$ constitutive repressive role of the mesenchymality is enforced by $\mathrm{NCoR}$ recruitment to $\mathrm{HNF} 4 \alpha$ regulatory 
A

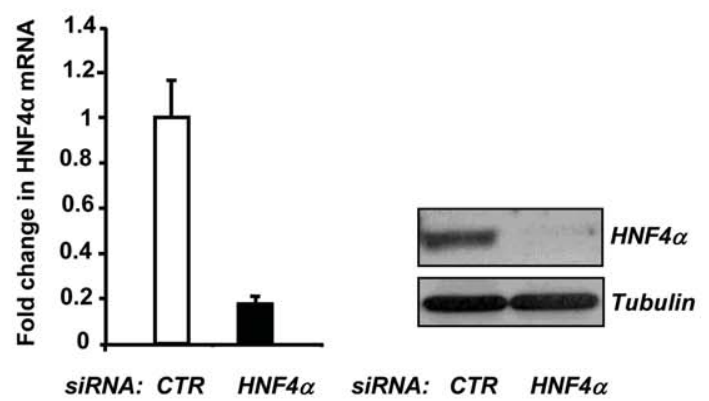

C

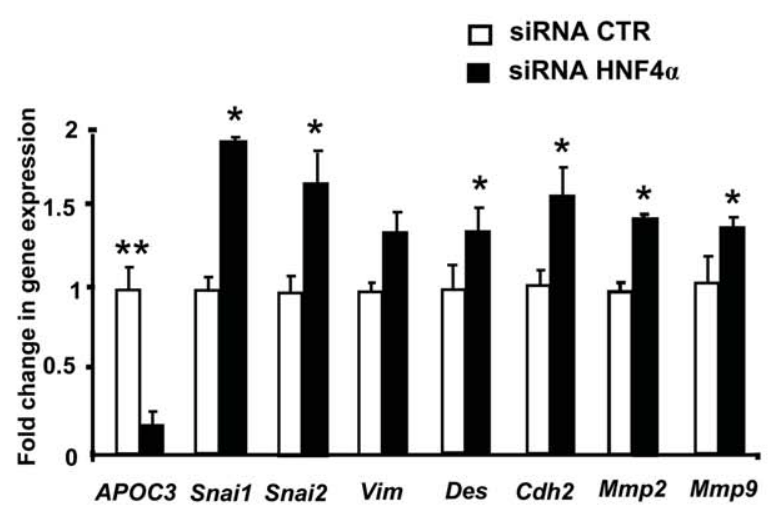

$\mathbf{E}$

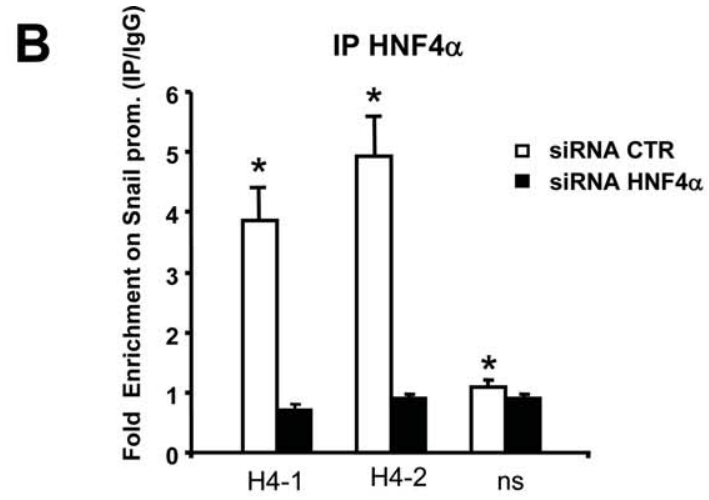

D
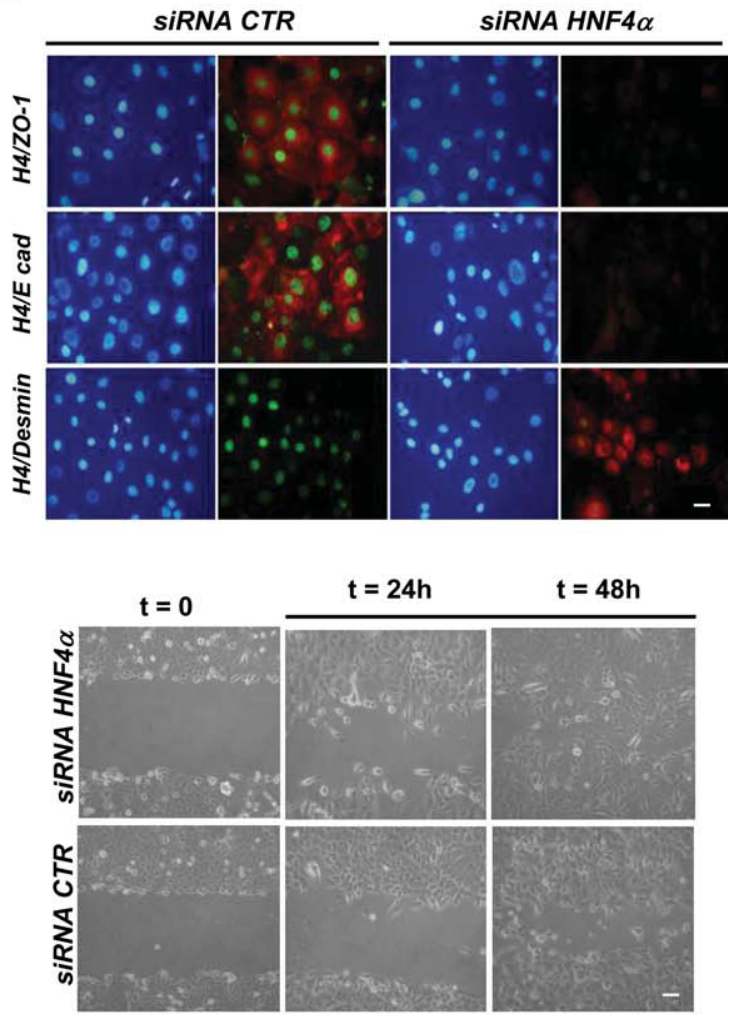

Fig. 5. HNF4 $\alpha$ knockdown promotes acquisition of mesenchymal features in hepatocytes. (A) Right: qPCR analysis showing the fold change in HNF4 $\alpha$ mRNA levels in control and HNF4 $\alpha$ siRNA-transfected MMH-D3 cells calculated using the $\Delta \Delta$ Ct method $(P<0.05)$. Left: Western blot analysis of HNF4 $\alpha$ protein levels in the same cells. (B) qPCR analysis of ChIP assay performed as described in Fig. 1E in siHNF4 $\alpha$ MMH-D3 cells. ${ }^{*} P<0.05$. (C) qPCR analysis of the indicated genes in control siRNA and HNF4 $\alpha$ siRNA transfected MMH-D3 cells calculated using the $\Delta \Delta$ Ct method. $* P<0.05, * * P<0.01$ (Student $t$ test). (D) Immunofluorescence staining for the indicated proteins in control siRNA and HNF4 $\alpha$ siRNA transfected MMH-D3 cells. Scale bar, $40 \mu \mathrm{m}$. (E) Left: Quantitation of migrating MMH-D3 cells transfected with control and HNF4 $\alpha$ siRNA in scratch assays performed for the indicated times. Data represent the mean cell counts per field in two independent experiments. Right: Representative phase micrographs of the same assays. Scale bar, 80 microns.

regions in the promoters of Snail and several mesenchymal genes.

In addition, knockdown of HNF $4 \alpha$ provides further evidence for its direct repression of mesenchymal targets. Using both cell culture and liver-specific $H n f 4 \alpha$ knockout mouse models, we demonstrate a direct correlation between loss of $\mathrm{Hnf} 4 \alpha$ and up-regulation of the mesenchymal genes. Histological examination of liver sections from Alb-Hnf4$\alpha^{-1-}$ mice showed that hepatocytes with the known hypertrophic phenotype express vimentin, desmin, fibronectin, and $\alpha$-smooth muscle actin and this with no noted increase in nonparenchymal cells. ${ }^{14}$

Although the cell culture model suggests a more dramatic influence of HNF $4 \alpha$ loss on the transition to mesenchymality, within the context of the whole 
A
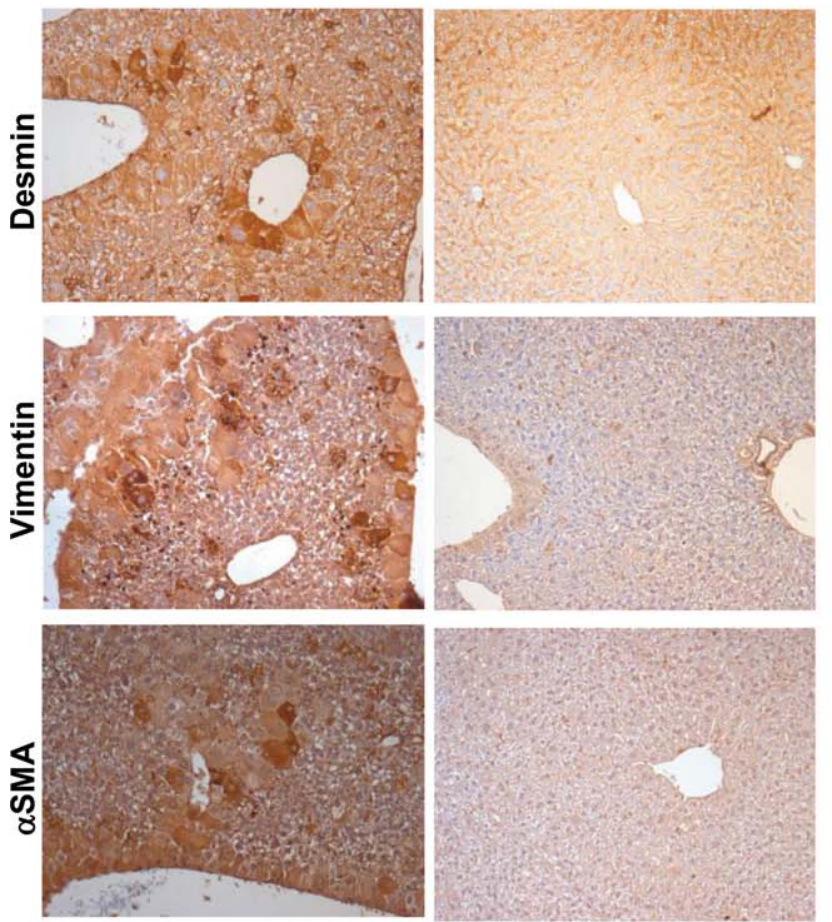

Alb-Hnf4 $\alpha-/-$
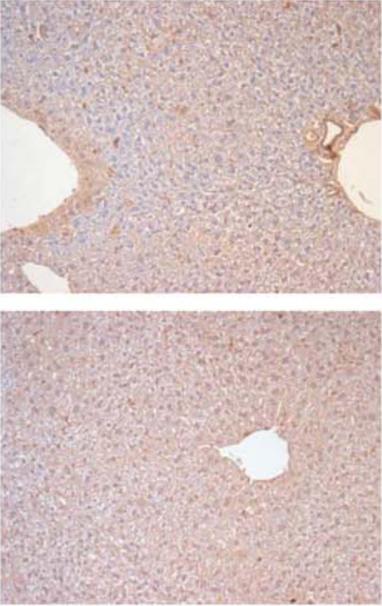

Alb-Hnf $4 \alpha$ F/F
B

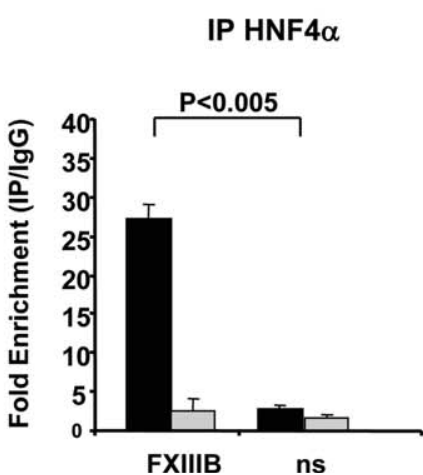

IP HNF4 $\alpha$

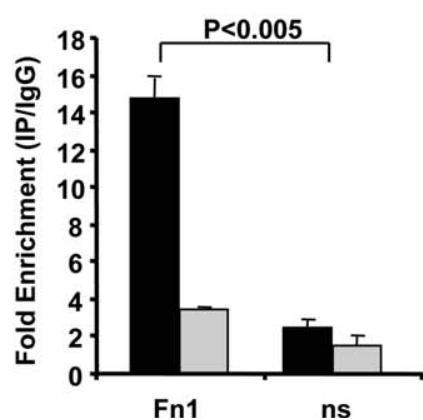

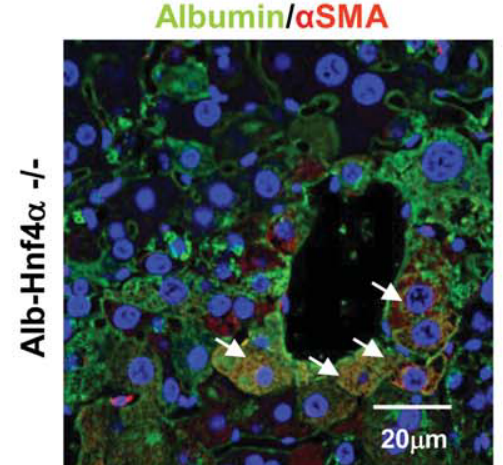

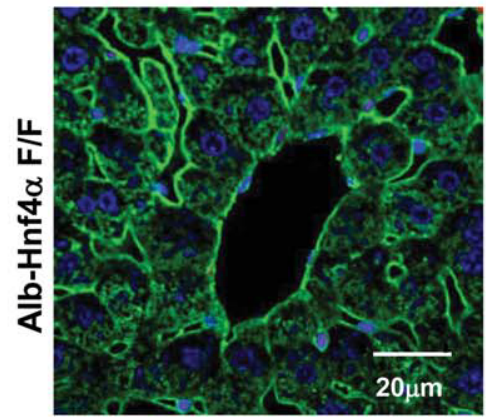

Fig. 6. HNF4 $\alpha$ knockout mice express mesenchymal genes. (A) Left: Immunohistochemical analysis of liver samples from wild-type (F/F) and Hnf $4 \alpha$ knockout (-/-) mice for the indicated mesenchymal markers. Right: Confocal microscopy analysis of two representative liver samples from the same mice showing the costaining of albumin and $\alpha$-smooth muscle actin ( $\alpha$ SMA (white arrows)). (B) qPCR analysis of ChIP assay performed with total liver tissue extracts $(n=2)$ showing HNF4 $\alpha$ recruitment on FXIIIB used as positive control on fibronectin (Fn1) and on Snail $(-728 /$ -703) promoters. Mean \pm SD of promoter sequence amplification compared with nonspecific (ns) region are reported with $P$ values $(P<$ $0.005, P<0.02)$.

animal, Hnf $4 \alpha$ depletion results in only a partial transition to the mesenchymal phenotype. In particular, while comparable quantification of in vivo HNF $4 \alpha$ recruitment was found between whole liver and $\mathrm{MMH}$ cells for the fibronectin promoter, enrichment was not as consistent for the Snail promoter. This may be a reflection of epigenetic differences between cell lines and in vivo hepatocytes. After embryonic development, it is conceivable that the Snail promoter is hypermethylated in the adult hepatocyte to maintain differentiation. If this occurs, it might interfere with $\mathrm{Hnf} 4 \alpha$ binding and thus explain the weak enrichment for HNF $4 \alpha$ on the Snail promoter in the in vivo ChIP assay. In line with this hypothesis is the observation that the Snail promoter CpG island is hypermethylated in the early stages of a mouse skin tumorigenesis 
model but is demethylated at a later, metastatic stage coincident with the repression of E-cadherin expression. ${ }^{30}$

Previously, we demonstrated that Snail represses $H n f 4 \alpha$ transcription through direct promoter binding. ${ }^{6}$ We propose a simple cross-regulatory circuit between Snail and HNF $4 \alpha$ in which the expression of each factor is mutually exclusive to the other due to the presence of repressor elements in each promoter. HNF $4 \alpha /$ Snail reciprocal control may provide the molecular rationale for feedback and reversible differentiative processes and explain, at least in part, the coherence and the reversibility of the molecular events underlying EMT/MET. In our cellular model, TGF $\beta$ induces EMT through Snail-dependent and Snailindependent mechanisms. ${ }^{6,7}$ Although further efforts are required to clarify this process, our preliminary evidence suggests that this includes HNF $4 \alpha$ functional inactivation.

Notably, we provide evidence extending an antimesenchymal role to $\mathrm{HNF} 1 \alpha$, another important liverenriched transcription factor. HNF $1 \alpha$ is positively regulated by $\mathrm{HNF} 4 \alpha$ and was recently proposed to have transcriptional repressor function on genes potentially involved in hepatocyte tumorigenesis. ${ }^{31}$ Our findings indicate that HNF $4 \alpha$ and $\operatorname{HNF} 1 \alpha$ transcriptional repression of critical mesenchymal genes is pivotal for the maintenance of a stable epithelial phenotype as well as for the regulation of the dynamic process of MET. In conclusion, our data integrate the well-established notion of the pivotal positive role of $\mathrm{HNF} 4 \alpha$ in hepatocyte differentiation through expression of epithelial genes with the new concept of active repression of mesenchymal genes.

Acknowledgment: We thank Amparo Cano (Biomedical Research Institute, Madrid, Spain) for the pX1Snail luciferase plasmid and Stephen A. Duncan (Medical College of Wisconsin, Milwaukee, WI) for the pCMV-HNF $4 \alpha$ rat plasmid. We thank Claudio Cavallari and Tsutomu Matsubara for technical assistance. We also thank the pathologist Mara Riminucci (Sapienza, University of Rome) for her helpful comments.

\section{References}

1. Thiery JP, Acloque H, Huang RY, Nieto MA. Epithelial-mesenchymal transitions in development and disease. Cell 2009;139:871-890.

2. Cano A, Perez-Moreno MA, Rodrigo I, Locascio A, Blanco MJ, del Barrio, MG, et al. The transcription factor snail controls epithelial-mesenchymal transitions by repressing E-cadherin expression. Nat Cell Biol 2000;2:76-83.

3. Hajra KM, Chen DY, Fearon ER. The SLUG zinc-finger protein represses E-cadherin in breast cancer. Cancer Res 2002;62:1613-1618.

4. Barrallo-Gimeno A, Nieto MA. The Snail genes as inducers of cell movement and survival: implications in development and cancer. Development 2005;132:3151-3161.
5. Choi SS, Diehl AM. Epithelial-to-mesenchymal transitions in the liver. HEPATOLOGY 2009;50:2007-2013.

6. Cicchini C, Filippini D, Coen S, Marchetti A, Cavallari C, Laudadio I, et al. Snail controls differentiation of hepatocytes by repressing HNF4alpha expression. J Cell Physiol 2006;209:230-238.

7. Cicchini C, Laudadio I, Citarella F, Corazzari M, Steindler C, Conigliaro A, et al. TGFbeta-induced EMT requires focal adhesion kinase (FAK) signaling. Exp Cell Res 2008;314:143-152.

8. Kaimori A, Potter J, Kaimori JY, Wang C, Mezey E, Koteish A. Transforming growth factor-betal induces an epithelial-to-mesenchymal transition state in mouse hepatocytes in vitro. J Biol Chem 2007;282: 22089-22101.

9. Sicklick JK, Choi SS, Bustamante M, McCall SJ, Perez EH, et al. Evidence for epithelial-mesenchymal transitions in adult liver cells. Am J Physiol Gastrointest Liver Physiol 2006;291:G575-G583.

10. Battle MA, Konopka G, Parviz F, Gaggl AL, Yang C, Sladek FM, et al. Hepatocyte nuclear factor 4alpha orchestrates expression of cell adhesion proteins during the epithelial transformation of the developing liver. Proc Natl Acad Sci U S A 2006;103:8419-8424.

11. Parviz F, Matullo C, Garrison WD, Savatski L, Adamson JW, Ning G, et al. Hepatocyte nuclear factor 4 alpha controls the development of a hepatic epithelium and liver morphogenesis. Nat Genet 2003;34:292-296.

12. Lazarevich NL, Cheremnova OA, Varga EV, Ovchinnikov DA, Kudrjavtseva EI, Morozova OV, et al. Progression of HCC in mice is associated with a downregulation in the expression of hepatocyte nuclear factors. HEPATOLOGY 2004;39:1038-1047.

13. Yue HY, Yin C, Hou JL, Zeng X, Chen YX, Zhong W, et al. Hepatocyte nuclear factor 4alpha attenuates hepatic fibrosis in rats. Gut 2010; 59:236-246.

14. Hayhurst GP, Lee YH, Lambert G, Ward JM, Gonzalez FJ. Hepatocyte nuclear factor 4alpha (nuclear receptor 2A1) is essential for maintenance of hepatic gene expression and lipid homeostasis. Mol Cell Biol 2001;21:1393-1403.

15. Colletti M, Cicchini C, Conigliaro A, Santangelo L, Alonzi T, Pasquini E, et al. Convergence of Wnt signaling on the HNF4alpha-driven transcription in controlling liver zonation. Gastroenterology 2009;137: 660-672.

16. Spath GF, Weiss MC. Hepatocyte nuclear factor 4 provokes expression of epithelial marker genes, acting as a morphogen in dedifferentiated hepatoma cells. J Cell Biol 1998;140:935-946.

17. Torres-Padilla ME, Fougere-Deschatrette C, Weiss MC. Expression of HNF4alpha isoforms in mouse liver development is regulated by sequential promoter usage and constitutive $3^{\prime}$ end splicing. Mech Dev 2001;109:183-193.

18. Peinado H, Quintanilla M, Cano A. Transforming growth factor beta-1 induces snail transcription factor in epithelial cell lines: mechanisms for epithelial mesenchymal transitions. J Biol Chem 2003;278:21113- 21123.

19. Batlle E, Sancho E, Franci C, Dominguez D, Monfar M, Baulida J, et al. The transcription factor snail is a repressor of E-cadherin gene expression in epithelial tumour cells. Nat Cell Biol 2000;2:84-89.

20. Amicone L, Spagnoli FM, Spath G, Giordano S, Tommasini C, Bernardini $S$, et al. Transgenic expression in the liver of truncated Met blocks apoptosis and permits immortalization of hepatocytes. EMBO J 1997; 16:495-503.

21. Kuo CJ, Conley PB, Chen L, Sladek FM, Darnell JE Jr, Crabtree GR. A transcriptional hierarchy involved in mammalian cell-type specification. Nature 1992;355:457-461.

22. Eeckhoute J, Formstecher P, Laine B. Hepatocyte nuclear factor 4alpha enhances the hepatocyte nuclear factor 1alpha-mediated activation of transcription. Nucleic Acids Res 2004;32:2586-2593.

23. Rowley CW, Staloch LJ, Divine JK, McCaul SP, Simon TC. Mechanisms of mutual functional interactions between HNF-4alpha and HNF-1alpha revealed by mutations that cause maturity onset diabetes of the young. Am J Physiol Gastrointest Liver Physiol 2006;290:G466-G475.

24. Odom DT, Zizlsperger N, Gordon DB, Bell GW, Rinaldi NJ, Murray HL, et al. Control of pancreas and liver gene expression by HNF transcription factors. Science 2004;303:1378-1381. 
25. Thuault S, Valcourt U, Petersen M, Manfioletti G, Heldin CH, et al. Transforming growth factor-beta employs HMGA2 to elicit epithelialmesenchymal transition. J Cell Biol 2006;174:175-183.

26. Nagaki M, Moriwaki H. Transcription factor HNF and hepatocyte differentiation. Hepatol Res 2008;38:961-969.

27. Stanulovic VS, Kyrmizi I, Kruithof-de Julio M, Hoogenkamp M, Vermeulen JL, et al. Hepatic HNF4alpha deficiency induces periportal expression of glutamine synthetase and other pericentral enzymes. HEPATOLOGY 2007; 45:433-444.

28. Satohisa S, Chiba H, Osanai M, Ohno S, Kojima T, Saito T, et al. Behavior of tight-junction, adherens-junction and cell polarity proteins during HNF-4alpha-induced epithelial polarization. Exp Cell Res 2005;310:66-78.
29. Bolotin E, Liao H, Ta TC, Yang C, Hwang-Verslues W, et al. Integrated approach for the identification of human hepatocyte nuclear factor 4alpha target genes using protein binding microarrays. HEPATOLOGY 2010;51:642-653.

30. Fraga MF, Herranz M, Espada J, Ballestar E, Paz MF, et al. A mouse skin multistage carcinogenesis model reflects the aberrant DNA methylation patterns of human tumors. Cancer Res 2004;64: 5527-5534.

31. Pelletier L, Rebouissou S, Paris A, Rathahao-Paris E, Perdu E, BioulacSage P, et al. Loss of hepatocyte nuclear factor 1alpha function in human hepatocellular adenomas leads to aberrant activation of signaling pathways involved in tumorigenesis. HEPATOLOGY 2010;51: 557-566. 